\title{
Multidimensional Unfolding of Children's Causal Beliefs: One Aspect of Construct Validation
}

\author{
Yeong K. Lee and Seong-Sor Lee \\ University of British Columbia
}

\begin{abstract}
A two-dimensional assessment device of children's causal beliefs was constructed on the basis of four perceived causes of success and failure consequences, given 12 situations, each describing circumstances for a consequence. The four perceived causes, ability (A), effort $(\mathbb{E})$, task difficulty $(\mathbb{T})$, and luck $(\mathbb{L})$, were defined in terms of two a priori dimensions (i.e., internality and stability) according to Weiner's (1974) theory of causal attribution. Four hundred and fifty-nine Grade 3, 4, 5, and 6 children were asked to make preference judgments over 72 paired comparisons. The data matrices thus obtained were subjected to a multidimensional preference scaling method based on a vector model (Carroll, 1972). The internal analysis recovered the two causal dimensions perceived by children as hypothesized by the model. This internal structural aspect of the construct validity was found to be accompanied by a moderately high test-retest reliability.
\end{abstract}

Numerous scales of internal-external (I-E) control for adults (Dies, 1968; Rotter, 1966) and for children (Crandall, Katkovsky, \& Crandall, 1965; Gruen, Korte, \& Baum, 1974; Mischel, Zeiss, \& Zeiss, 1974; Nowicki \& Duke, 1974; Nowicki \& Strickland, 1973; Stephens \& Delys, 1973) have been developed. These scales were designed to measure individual differences in generalized expectancies or beliefs about the locus of control. A number of studies concerning the dimensionality

APPLIED PSYCHOLOGICAL MEASUREMENT

Vol. 7, No. 3, Summer 1983, pp. 323-332

(C) Copyright 1983 Applied Psychological Measurement Inc. 0146-6216/83/030323-10\$1.75 of I-E scales (Collins, 1974; Mischel et al., 1974; Nowicki \& Strickland, 1973) have reported that the factor analysis of the $\mathbb{I}-\mathbb{E}$ scales resulted in multiple dimensions or components, suggesting subscales within each I-E scale.

Distinctively lacking in this area is an assessment device that is based on a useful theoretical construct accompanied by validity data. The purpose of the present study was to develop a locus of control assessment device constructed from Weiner's (1974) theory of two-dimensional causal attribution and, further, to demonstrate how a multidimensional scaling technique (Carroll, 1972) can be applied to the unfolding of two a priori dimensions which initially provided a basis for constructing assessment items.

\section{Substantive Theory}

Weiner, Heckhauser, Meyer, and Cook (1972) and Weiner and Sierad (1975) investigated the relationship between the levels of achievement needs of individuals and the patterns of causal attributions following success or failure. More specifically, they hypothesized that individuals low in achievement needs have a tendency to ascribe failure to their inability (an internal and relatively stable cause), and then to experience low expectancies of future success, since the stable-internal attribute (inability in this case) is not likely to change for the next trial or task situation (e.g., I am not good at it, 
and I won't be able to do it). On the other hand, individuals high in their achievement needs have a tendency to ascribe failure to a lack of effort (also an internal but unstable cause) and experience relatively high expectancy of success after failure, since the amount of effort is perceived to be under their control (e.g., I can do it if I try harder next time). In other words, both types of individuals, high or low in achievement needs, ascribe failure to internal determinants. Depending upon whether the causal determinant of failure is stable or unstable (invariable or variable), however, the achievement strivings can be inhibited or enhanced after experiencing failure.

In order to distinguish two internal causes-inability and lack of effort in the above case-Weiner (1974) proposed, following Heider (1958), a two-dimensional classification scheme of the perceived causes of success or failure. One dimension is the internal-external locus of control as conceived by Rotter (1966); and the other, stable-unstable causes. As shown in Table $\mathbb{1}$, task difficulty and luck are both external determinants; but task difficulty is a relatively stable determinant, whereas luck is an unstable one. From the two-dimensional framework, it can be readily noticed that the locus of control and stability dimensions of causality have been confounded in previous experimental studies as well as in I-E scales. For example, Item 9 of the Intellectual Achievement Responsibility Scale (Crandall et al., 1965) reads as follows:

If you solve a puzzle quickly, is it

(a) because it wasn't a very hard puzzle, or

(b) because you worked on it carefully?

In this item, (a) is a task difficulty cause (externalstable) and (b) is an effort cause (internal-unstable). Another example of confounding can be found in the Pre-school and Primary Internal-Extemal Control Scale (Nowicki \& Duke, 1974) as in Item 28, which reads, "Do you think it's better to be smart than to be lucky?" Here, ability is contrasted with luck; thus, two dimensions are confounded. Rotter, Liverant, and Crowne (1961) have demonstrated that expectancy shifts are more frequent and of greater magnitude in skilled (ability) tasks than in chance controlled (luck) tasks. The contrast in this case can be interpreted in terms of the internalunstable dimension. What is needed here is the development of a new device based on an experimentally validated, coherent theory and the determination of whether children differentially ascribe certain consequences to two perceivable dimensions.

\section{Merhod}

\section{Develomment on the Device}

The measurement model of paired comparisons was chosen to obtain preference judgments over four alternative causal ascriptions, given each item (situation). Twelve situations, six success and six failure, were created for children in Grades 3 to 6 (the situations are listed in the first column of Table 2). These situations were selected from the stories written by Grade 6 children about their favorite activities. They included four individual ac. ademic, four individual nonacademic, and four group nonacademic situations.

For each situation, four causal statements were chosen according to the two-dimensional classification described in Table 1 . For example, the first item for success was:

Table 1

Clasification of Perceived Causes of

Success or Failure

\begin{tabular}{|c|c|c|c|}
\hline \multirow[b]{2}{*}{ Stability } & \multicolumn{3}{|c|}{ Locus of Control } \\
\hline & Internal & External & \\
\hline Stable & Ability (A) & Task Difficulty & $(\mathrm{T})$ \\
\hline Unstable & Effort (E) & Luck & (L) \\
\hline
\end{tabular}


Q. Sally did very well on our spelling test. Why do you think this happened?

(a) She is good at spelling. (ability)

(b) The spelling test was easy. (task difficulty)

(c) She studied a lot for the test. (effort)

(d) She was lucky. (luck)

These 4 alternatives were paired in all possible combinations yielding 6 paired comparisons for each situation. The scheme of obtaining preference judgments reflected in response patterns across 6 paired comparisons for each of 12 items, which were also systematically structured in 3 domains of 4 items, should improve the structural fidelity of the device (Wiggins, 1973, pp. 398-409).

\section{Subjects and Procedure}

A total of 459 children from 2 public schools (i.e., 117 from Grade 3, 143 from Grade 4, 74 from Grade 5, and 125 from Grade 6) participated. Each was given the 12-item assessment device, each item involving 6 paired comparisons out of 4 causal statement alternatives (i.e., $\left(\frac{4}{2}\right)=6$ pairs.) The 6 pairs for each item were typed on a $8 \times 11$ inch sheet of white paper. All subjects took the 13page booklet including a practice item, each listing 6 pairs.

The 6 pairs were randomly sequenced within each situation in order to minimize any systematic response biases, and the success and failure situations were alternated in order of presentation. In all there were 72 pairs of statements, and subjects were asked to choose one from each pair. All causal statements were in third- rather than first-person format so that subjects could respond to questions regarding activities in which they do not, in reality, participate. It was assumed that the third-person format would help elicit semiprojective responses. A pilot run of a set of 12 items with a group of children from Grades 3 and 6 was analyzed, and causal statements were revised on this basis for better wording.

The assessment device was given to 78 Grade 5 children 2 weeks later to determine a test-retest reliability and to 146 Grade 6 children 6 months later to determine a stability index. Three Grade 5 and 19 Grade 6 children did not take it the second time; these were discarded for the computation of the test-retest reliability and stability index.

\section{Structural Analysis of Paired Comparison Data and the PDorness-of-Fit Test}

Pairing 4 response alternatives for each item into 6 possible pairs for preference judgement resulted in 12 four $x$ four lower triangular matrices. The goal of internal analysis of the matrices was to determine how closely the two a priori dimensions-locus of control (internal vs. external) and variability (stability vs. unstability) - could be recovered from the preference ordering of 4 causal alternatives unfolded out of 6 preference judgments (Wiggins, 1973). If the recovered dimensions coincided with a priori ones, then it could be claimed that the device developed has empirical construct validity as hypothesized. The nonmetric multidimensional scaling method used in the present study is well described in Carroll (1972). This method is basically an internal analysis of preference data based on the vector model, which was first proposed by Tucker (1960). This analysis can reveal only those dimensions that are used differentially by different subjects in making paired comparisons. In other words, only those dimensions or factors that contribute to individual differences in response to the causal statements can be discovered by this analysis. If they respond in exactly the same way, the preference analysis will yield a single dimension that is a composite of those otherwise differentiable dimensions.

MDPREF, the computer program written by Chang and Carroll (1968), was adjusted for up to 100 subjects and used for the analysis of paired comparison data. ${ }^{1}$ For each of 12 stimulus (actually consequence) situations, a total of 10 dimensional

\footnotetext{
'An application of a confirmatory testing model proposed by Davison (1980) seemed inappropriate for the present internal analysis of preference ordered data. The paired comparison judgment used is a type of forced rank ordering of all four causal explanations, which violates his first assumption (p. 132, Davison, 1980). In his model the number of objects selected by subjects should remain the same, but the selected objects per se can vary. By relaxing this assumption, this model, instead of the MDPREF model, could have been employed at the firststage analysis of the data.
} 
configurations was obtained from 7 pretest groups and 3 retest groups. The 7 included 2 groups of Grades 3,4, and 6 each and one group of Grade 5 ; the 3 retest groups included 1 group of grade 5 and 2 groups of Grade 6 children. Thus, there were a total of $120(10$ groups $\times 12)$ configurations obtained in all. The reason for obtaining 10 different configurations was two-fold. First, to modify and run the computer program to handle more than 100 subjects, thereby larger than $100 \times 100$ matrices, would require a prohibitive amount of computing resources. Second, it would be interesting to see to what extent a dimensional configuration for each item (situation) could be replicated over 10 different groups despite their age differences.

\section{Results and Discussion}

Preference judgment data were analyzed to seek evidence (1) to determine the structure of underlying dimensions, thereby testing the poomess of fit of the data to the model and (2) to determine some reliability index of the dimensions extracted.

\section{耳nternal Stracture and

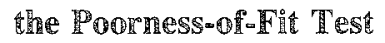

Weiner's (1974) substantive theory described earlier can be represented in terms of preference analysis. The two dichotomous dimensions underlying causal explanations are (1) internal-external and (2) stable-unstable. The factorial combination of the two dimensions results in the four types of causal explanations: ability (A), task (T), effort $(E)$, and luck $(\mathbb{L})$. The preference ordering for an individual of the four for a given situation depends on which dimension she/he sees as more preferable. For example, a person who prefers internalstable explanations (in that order) would produce a preference ordering a A-E-T-L (i.e., 3-2-1-0 in frequency of preferences), whereas a stable-internal ordering would be A-T-E-L. A person who prefers an internal explanation (but is indifferent to stability) would fluctuate between $A-\mathbb{E}-T-L$, A-E-L-T, E-A-T-L, and E-A-L-T over times. Orderings such as $A-L-E-T$ and $T-E-L-A$ violate the mode1. A-E-T-L or A-T-E-L given by the first category should result in two-dimensional MDPREF configurations, as shown in Figure 1. The second category corresponds to one-dimensional configuration, while the third yields no discernible dimensional solution.

Given four causal explanations, there are 24 possible orderings (i.e., $4 !)$ of $(3,2,1,0)$ response frequency patterns, 16 of which correspond to what the two-dimensional hypothesis predicts and 8 of which do not. There are also three sets of 24 orderings involving some ties: $(3,1,1,1),(2,2,2,0)$, and $(2,2,1,1)$. Thus, there is a total of 96 possible response frequency parterns, 80 of which contain intransitivities. The preference scaling procedure treats such intransitivities as errors in response and tries to find the ordering that produces the fewest numbers of intransitivities. In the present study, then, Weiner's model of two-dimensional causal attribution predicts the expected number of two-dimensional preference orderings to be $16 /$ $96=.167$.

Each dimensional configuration obtained from MDPREF was judged according to the following criteria: (1) good-4 points each located in a quadrant in equidistance; (2) acceptable - 4 points each located in a quadrant; (3) questionable - no definable dimension; and (4) reversed-binary values of a dimension reversed. The first two judged categories were considered to reflect a good fit. The cases of fit were tallied according to the criteria, with the 10 groups regarded as replicates. As can be seen in the fifth column of Table 2, there were 4 situations where goodness-of-fit proportions fell below the value expected according to the model, all of which happened to occur in the failure situations. A nonparametric sign test was performed for the 12 situations. The result indicated that 8 out of 12 situations were significantly greater $(p<.073)$ than the expected proportion $(p=167)$ from the model.

Overall, the two a priori dimensions, internality and stability, appeared to have been operative in preference judgment for all items except Items 4 , 8,10 , and 12. Items 4,8 , and 12 were represented predominantly in one dimension, internality; Item 10 , in stability. Item 5 , a typical item of the 8 good 
Tigurare 1

Stimulus Configuration for Item 5 with the First Two Dimensions

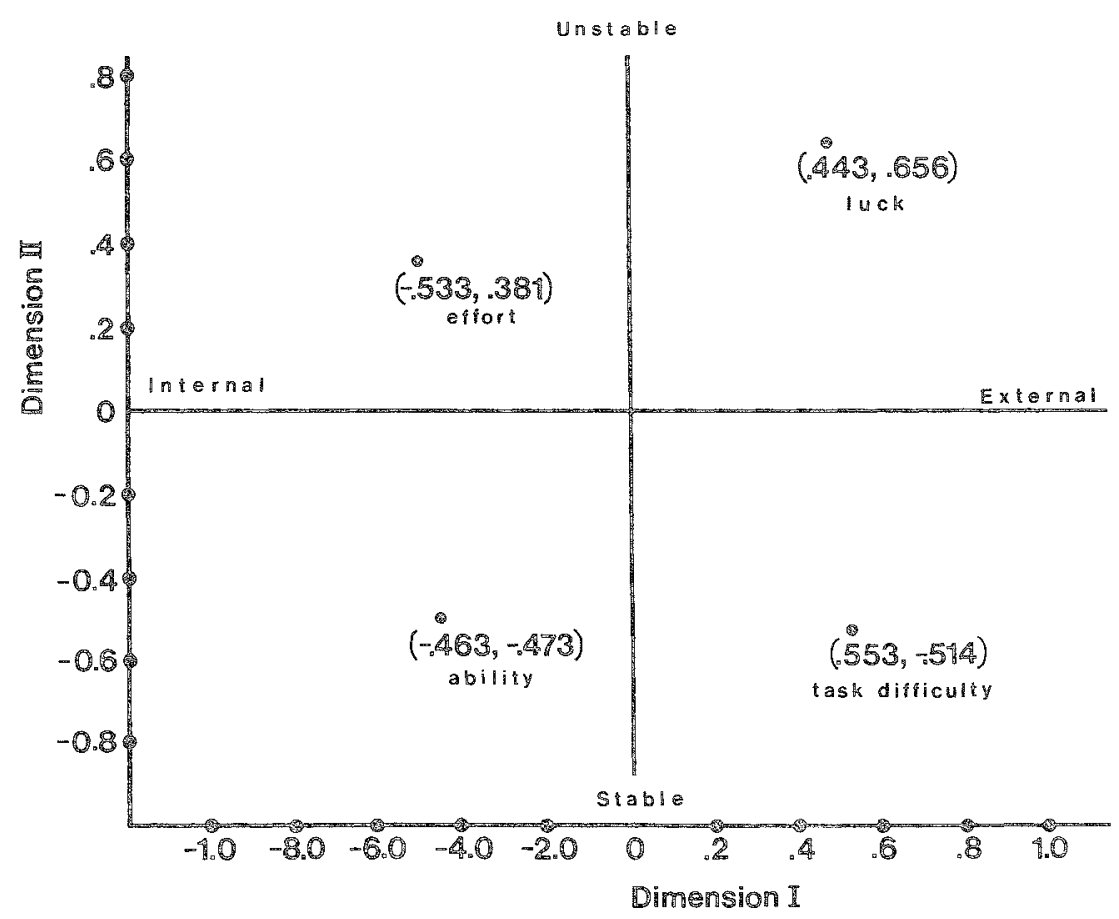

Table 2

Goodness-of-Fit to Model Proportions for 12 Items Unfolded Over 10 Different Groups of Children $(\mathbb{N}=459$ with 199 Retested)

\begin{tabular}{|c|c|c|c|c|c|}
\hline \multirow{3}{*}{$\begin{array}{c}\text { Item } \\
\text { No. }\end{array}$} & \multirow[b]{3}{*}{ Sicuation } & \multirow{2}{*}{\multicolumn{2}{|c|}{$1-$ Dimensional Fit }} & \multicolumn{2}{|c|}{ 2-Dimensional Fit } \\
\hline & & & & Internality- & Dimen- \\
\hline & & Internality & Stability & Stability & sion \\
\hline 1 & Academic Success & $10 / 10$ & $3 / 10$ & $3 / 10$ & 2 \\
\hline 2 & Academic Failure & $10 / 10$ & $4 / 10$ & $4 / 10$ & 2 \\
\hline 3 & Academic Success & $10 / 10$ & $7 / 10$ & $7 / 10$ & 2 \\
\hline 4 & Academic Failure & $10 / 10$ & $1 / 10$ & $1 / 10$ & $\mathbb{1}$ \\
\hline 5 & Ind-nonac Success & $9 / 10$ & $7 / 10$ & $7 / 10$ & 2 \\
\hline 6 & Ind-nonac Failure & $10 / 10$ & $5 / 10$ & $5 / 10$ & 2 \\
\hline 7 & Ind nonac Success & $10 / 10$ & $5 / 10$ & $5 / 10$ & 2 \\
\hline 8 & Ind-Nonac Failure & $8 / 10$ & $2 / 10$ & $1 / 10$ & 1 \\
\hline 9 & Grp-Nonac Success & $10 / 10$ & $8 / 10$ & $7 / 10$ & 2 \\
\hline 10 & Grp-Nonac Fallure & $1 / 10$ & $9 / 10$ & $1 / 10$ & 1 \\
\hline 11 & Grp-Nonac Success & $10 / 10$ & $7 / 10$ & $7 / 10$ & 2 \\
\hline 12 & Grp-Nonac Failure & $8 / 10$ & $2 / 10$ & $1 / 10$ & 1 \\
\hline
\end{tabular}

Downloaded from the Digital Conservancy at the University of Minnesota, http://purl.umn.edu/93227. May be reproduced with no cost by students and faculty for academic use. Non-academic reproduction requires payment of royalties through the Copyright Clearance Center, http://www.copyright.com/ 
items, has the structural configuration shown in Figure 1. The first dimension, which accounted for the largest proportion of variance $(63 \%)$, can be identified as internality and the second dimension, accounting for the second largest proportion of variance $(21 \%)$, can be identified as a stability dimension. It is interesting to note that the item situations which yielded not enough replications for the joint two-dimensional fit were mostly failure situations. This means that the interpretations of failure consequences are less consistent than those of success situations.

The proportions of variance accounted for by each dimension obtained from MDPREF, are shown in Table 3. On the average, 54\% of the total variance was accounted for by the internality dimension, and $28 \%$ of that, by the stability dimension. In all, $82 \%$ of the total variance was accounted for by these two dimensions.

In sum, the results of the multidimensional unfolding of preference judgments provided evidence that the subjects indeed responded to the device items differentially on these two dimensions when they ascribed causes of success or failure. Thus, the validity of the device built on the basis of the two-dimensional theory of causal attribution proposed by Weiner et al. (1972) and Weiner and Sierad (1975) seems to be empirically supported.

Although the proportion of variance accounted for by the stability dimension is much less than that of the internality dimension, as Weiner hypothesized, the stability dimension plays a significant role in providing information on the basis of which individuals are identified as different types. Particularly when most subjects in a group tend to be internal, the stability dimension plays an important role in further detecting individual differences in causal beliefs so that subjects may be classified as high or low in achievement motivation.

It is also noted that the proportions of variance accounted for by the internality dimension are larger in success situation items than in failure items. A sign test on 10 pairs of proportions showed a significant difference $(p<.001)$. Also, the proportions of variance accounted for by the stability dimension are smaller for success items than for failure items. (A sign test was significant, $p<.001$ ). Perhaps this means that the patterns of causal ascription following success are different from those following failure, at least for the subjects of the present study. In other words, the internality dimension plays a more dominant role for success situations than for failure, whereas the stability dimension plays a more significant role in causal ascriptions following failure than success. To test this hypothesis, further investigations are in order.

\section{Test-Hetest Rellabiliny and Stability of Dimensions}

In order to estimate test-retest reliability as well as the stability index of the dimensions, two dimensional scores, internality and stability, were obtained for each subject. The internality score was obtained by assigning " 1 " whenever internal causal

Table 3

Proportions of Variance Accounted for by the Two Dimensions and Four Grades

\begin{tabular}{|c|c|c|c|c|c|c|c|c|}
\hline \multirow[b]{2}{*}{ Grade } & \multirow[b]{2}{*}{$\mathrm{N}$} & \multicolumn{3}{|c|}{ Internality } & \multicolumn{3}{|c|}{ Stability } & \multirow[b]{2}{*}{ Total } \\
\hline & & Success & Failure & Mean & Success & Failure & Mean & \\
\hline 3 & 117 & .50 & .41 & .46 & .30 & .36 & .33 & .79 \\
\hline 4 & 143 & .56 & .43 & .50 & .25 & .34 & .30 & .80 \\
\hline 5 & 74 & .66 & .56 & .61 & .23 & .27 & .25 & .86 \\
\hline 6 & 125 & .67 & .48 & .58 & .19 & .32 & .26 & .84 \\
\hline Mean & & .60 & .47 & .54 & .24 & .32 & .28 & .82 \\
\hline
\end{tabular}


statements were chosen over external ones (i.e., $\mathrm{A}>\mathrm{T}, \mathrm{A}>\mathrm{L}, \mathrm{E}>\mathrm{T}, \mathrm{E}>\mathrm{L}$ ). Since there were 4 such pairs for each item, the maximum possible score for any subject was 48 . The stability score was obtained in a similar fashion (i.e., $\mathrm{A}>\mathbb{E}$, $\mathrm{A}>\mathrm{L}, \mathrm{T}>\mathrm{E}, \mathrm{T}>\mathrm{L}$ ). Higher scores imply greater "internal" or "stable" tendency.

The correlations between test and retest scores of internality and stability dimensions are shown in Table 4. The 2 weeks test-retest reliability estimates for Grade 5 were .77 (the Fisher approximate $95 \%$ confidence interval: .66 to .85) and .53 ( $95 \%$ confidence interval: .36 to .69) for internality and stability scores, respectively. The test-retest stability indices over a 6-month period for Grade 6 were .76 (95\% confidence interval: .68 to .83 ) and .47 (95\% confidence interval: .33 to .61$)$ for internality and stability scores, respectively. These moderately high stability indices, in combination with the finding that no significant mean score change was observed between Grades 5 and 6 (i.e., 35.88 to 36.18 for internality and 22.41 to 22.16 for stability score), suggest that by Grade 5, at least, internal attribution tendency becomes stabilized. In other words, internality is a more durable cognitive disposition working in attributional contexts. All other correlations were nonsignificant. This suggests independence of internality from stability scores. These results are in agreement with the results obtained from the MDPREF analysis.

\section{A Practical ltem Refinement Procedure via MOPRRE Analysis}

As noted earlier, the configuration of MDPREF analysis for each item is contingent upon subjects' preference orderings of four causal response alternatives. This means that preference orderings are influenced by how subjects interpret each item with four causal statements. It would be worth demonstrating how item descriptions could be refined or revised on the basis of configurations obtained by MDPREF.

Item 12 initially read as follows:

Jane's school band played very poorly at the Christmas concert. Why do you think this happened?

(a) Most kids in the band are not good musicians.

(b) They were playing very difficult music.

(c) They did not practice enough before the concert.

(d) Some of the kids in the band were not feeling well that day.

The stimulus configuration obtained for this item is shown in Figure 2. The first dimension can be interpreted as "controllability," as Weiner (1979)

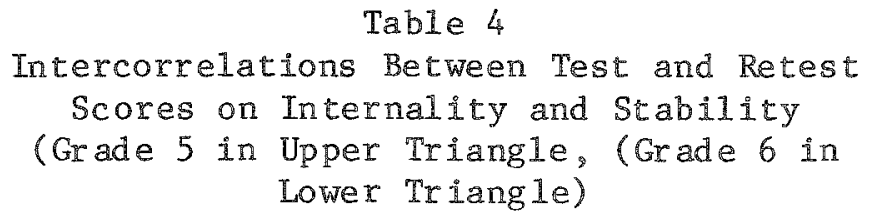

Table 4

Intercorrelations Between Test and Retest

Scores on Internality and Stability

(Grade 5 in Upper Triangle, (Grade 6 in Lowe $x$ Triangle)

\begin{tabular}{|c|c|c|c|c|}
\hline \multirow[b]{2}{*}{ Dimension } & \multicolumn{2}{|c|}{ Internality } & \multicolumn{2}{|c|}{ Stability } \\
\hline & Test & Retest & $\overline{\text { Test }}$ & Retest \\
\hline \multicolumn{5}{|c|}{ Internality } \\
\hline Test & & $.771 \%$ & $\omega_{\circ} 382$ & -.106 \\
\hline Retest & $.765 *$ & & -.070 & -161 \\
\hline \multicolumn{5}{|l|}{ Stability } \\
\hline Test & -.247 & -162 & & $.535 *$ \\
\hline Retest & -.173 & -.110 & $.474 *$ & \\
\hline
\end{tabular}

* Significant at $p<.01$. 
Figure 2

Stimulus Configuration for Item 12 of the Original Form with the First Two Dimensions-Controllability and Unknown

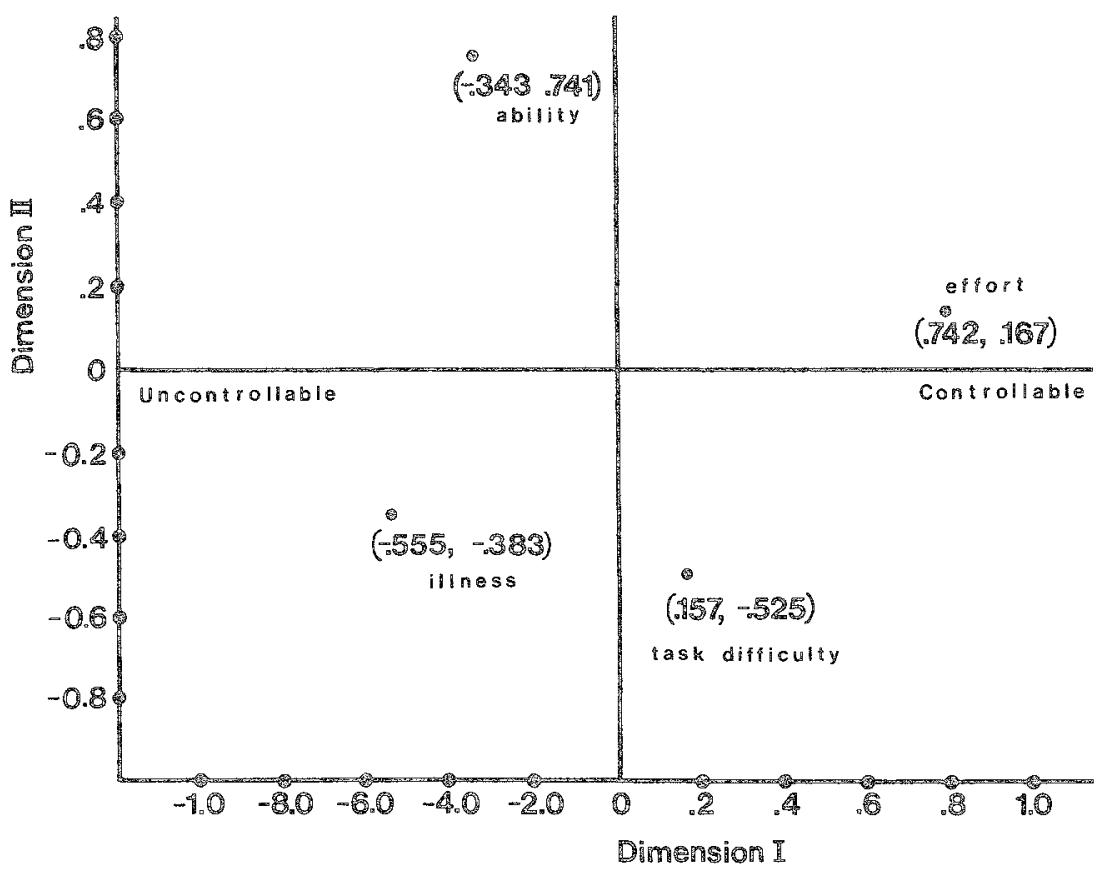

proposed, since the causes (a) and (d) are uncontrollable and (b) and (c) are controllable. In this example, the internality dimension did not emerge, since internal causes (a), (b), and (d) did not load on any dimension as a cluster. The causal statements (b) and (d) were revised as follows:

(b) The music that they were playing was a difficult one.

(c) The audience was noisy that time.

The configuration obtained from this revised item is shown in Figure 3. Now the first dimension is clearly internality, and the second dimension can be interpreted as controllability, since (b) and (c) are controllable causes, whereas (a) and (d) are not. This example shows that MDPREF analysis can also be used as a valid procedure for refining assessment item statements.

\section{洫eferences}

Carroll, J. D. Individual differences and multidimensional scaling. In R. N. Shepard, A. K. Romney, \&
S. B. Nerlove (Eds.), Multidimensional scaling: Theory and application in the behavioral sciences. Vol.1: Theory. New York/London: Seminar Press, 1972.

Collins, B. E. Four components of Rotter Internal-External Scale: Belief in a difficult world, a just world, a predictable world, and a politically responsive world. Journal of Personality and Social Psychology, 1974, $29,381-391$.

Chang, J. J., \& Carroll, J. D. How to use MDPREF, a computer program for multidimensional analysis of preference data. Holmdel NJ: Bell Telephone Laboratories, Unpublished report, 1968.

Crandall, V. C., Katkovsky, W., \& Crandall, V.J. Children's belief in their own control of reinforcements in intellectual achievement situations. Child Development, 1965, 36, 91-109.

Davison, M. L. A psychological scaling model for testing order hypotheses. British Journal of Mathematical and Statistical Psychology, 1980, 33, 123-141.

Dies, R. $\mathbb{R}$. Development of a projective measure of perceived locus of control. Journal of Projective Techniques and Personality Assessment, 1968, 32, 487490.

Gruen, G. E., Korte, J. R., \& Baum, J. F. Group measure of locus of control. Developmental Psychology, $1974,10,683-686$. 
Tigure 3

Stimulus Configuration of Item 12 Revised with the first Two Dimensions-Internality and Controllability

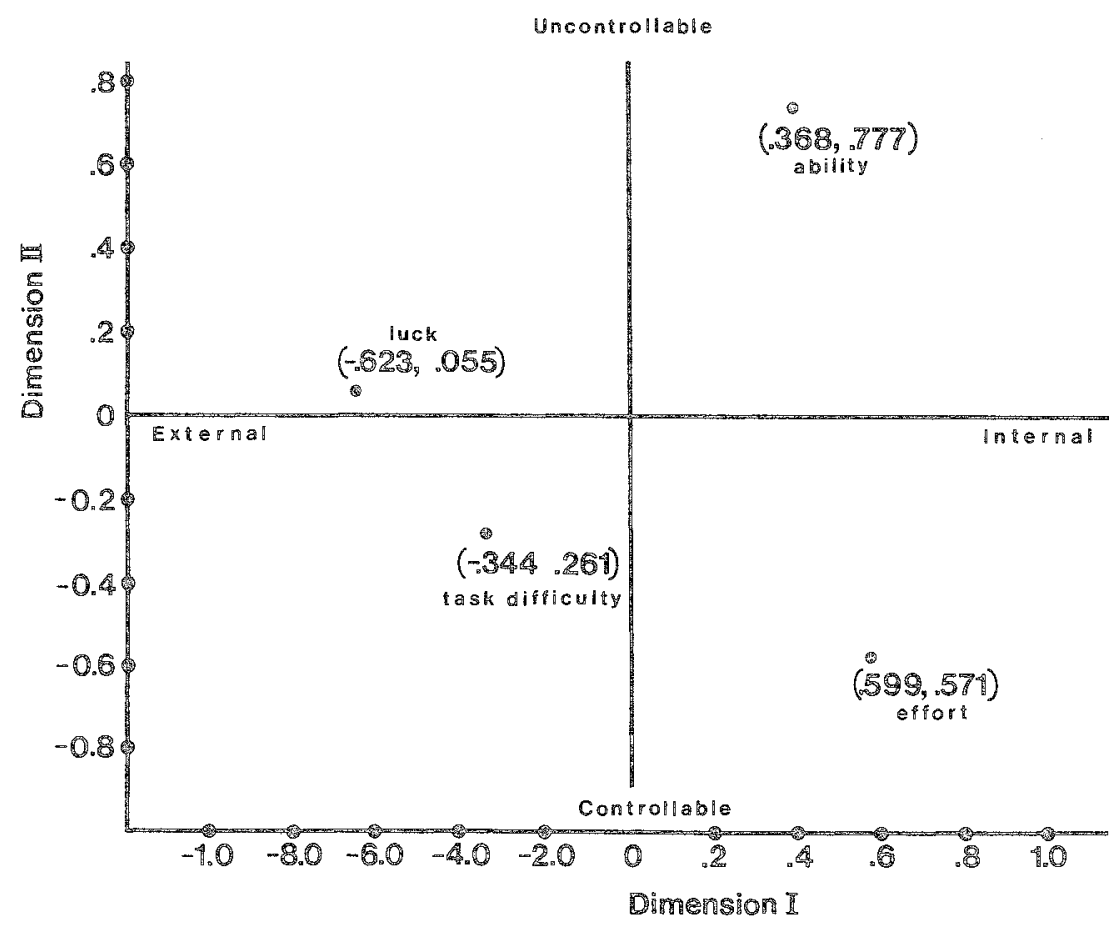

Heider, F. The psychology of interpersonal relations. New York: Wiley, 1958.

Mische1, W., Zeiss, R., \& Zeiss, A. Internal-external control and persistence: Validation and implications of the Stanford Preschool Internal-External Scale. Journal of Personality and Social Psychology, 1974, $29,265-278$.

Nowicki, S., \& Duke, M. P. A preschool and primary internal-external control scale. Developmental Psychology, 1974, 10, 874-880.

Nowicki, S., \& Strickland, B. R. A locus of control scale for children. Journal of Consulting and Clinical Psychology, 1973, 40, 148-155.

Rotter, J. B., Liverant, S., \& Crowne, D. P. The growth and extinction of expectancies in chance-controlled and skilled tasks. Journal of Psychology, 1961, 52, $161-177$.

Rotter, J. B. Generalized expectancies for internal versus external control of reinforcement. Psychological Monographs, 1966, 80 (1, Whole No. 609).

Stephens, M. W., \& Delys, P. A locus of control measure for preschool children. Developmental Psychology, 1973, 9, 55-56.
Tucker, L. R. Intra-individual and inter-individual multidimensionality. In H. Gulliksen \& S. Messick (Eds.), Psychological scaling: Theory and application. New York: Wiley, 1960

Weiner, B. Achievement motivation as conceptualized by an attribution theorist. In B. Weiner (Ed.), Achievement motivation and attribution theory. Morristown NJ: General Learning Press, 1974.

Weiner, B., Heckhausen, H., Meyer, W. 1., \& Cook, R. E. Causal ascription and achievement motivation: An attributional analysis of effort and reanalysis of locus of control. Journal of Personality and Social Psychology, 1972, 21, 239-248.

Weiner, B. R. A theory of motivation for some classroom experiences. Joumal of Educational Psychology, 1979, 71, 3-25.

Weiner, B. R., \& Sierad, J. Misattribution for failure and enhancement of achievement strivings. Journal of Personality and Social Psychology, 1975, 31, 415 421.

Wiggins, J. S. Personality and prediction: Principles of personality assessment. Reading MA: Addison-Wesley, 1973. 


\section{Acknowledgment}

The authors are grateful for the computing funds readily made available through the Faculty of Education, University of British Columbia.

\section{Aathor's Address}

Send requests for reprints or further information to SeongSoo Lee, Department of Educational Psychology and Special Education, University of British Columbia, Vancouver BC V6T 125 , Canada.

Downloaded from the Digital Conservancy at the University of Minnesota, http://purl.umn.edu/93227.

May be reproduced with no cost by students and faculty for academic use. Non-academic reproduction requires payment of royalties through the Copyright Clearance Center, http://www.copyright.com/ 